\title{
LA ENSEÑANZA DE EUGENIO TRUEBA: LA CONSTANTE VOLUNTAD DE LA JUSTICIA ${ }^{1}$
}

\author{
Jesús Antonio DE LA TORRE RANGEL 2
}

El 24 de marzo de 2010 -hace ya casi cinco años- tuve el gusto de estar aquí, en la Universidad de Guanajuato, presentando el libro Guía Temática de Filosofía del Derecho, del maestro Eugenio Trueba Olivares. Hoy, nuevamente tengo la alegría de estar refiriéndome a la obra jurídica de Don Eugenio, en este homenaje tan merecido que le rinde esta Casa de Estudios.

Quiero comenzar diciendo que no tengo duda de que Eugenio Trueba Olivares es uno de los filósofos del Derecho más importantes que hay en México. Cultivador profundo y original del iusnaturalismo clásico; corriente iusfilosófica urgente de enseñar y de practicar.

En efecto, varias generaciones de abogados han sido formados en México, desde fines del siglo XIX y hasta nuestros días, siguiendo los lineamientos del positivismo jurídico; ya sea éste de corte voluntarista, repitiendo y aplicando los dogmas de la Escuela de la Exégesis, tales como "El Derecho es la ley" y "la ley es la voluntad del legislador"; o bien aceptando el positivismo normalógico de corte kelseniano, que identifica el Derecho con los aspectos formales, con la estructura lógica de las normas. Se trata, por un lado, de una visión del Derecho que lleva a celebrar el culto de la ley, su deificación; y por otro, a reducir lo jurídico al estrecho margen de las normas. Positivismos jurídicos avalorativos, con un trasfondo de neutralidad axiológica; positivismos jurídicos inhumanos, que sostienen que la persona -el sujeto de Derecho- no es el ser humano sino un conjunto de derechos y obligaciones que encuentra su origen en la ley.

Afortunadamente no han faltado profesores de Filosofía del Derecho, que desde su cátedra y/o sus libros, han enseñado el Derecho de otro modo; y han aportado y están aportando a la cultura jurídica mexicana, una visión distinta. Don Eugenio Trueba, es uno de ellos, desde su visión de iusnaturalismo clásico.

Consideramos, en su momento, que la Guía Temática de Filosofía del Derecho es una pequeña, pero muy sustanciosa obra, que nos muestra los temas básicos de la Filosofía del Derecho. Es, como su nombre lo indica, una guía de temas esenciales para un curso básico de la materia. No es un tratado de Filosofía Jurídica, sin embargo no se limita a indicar el tema a desarrollar, sino que, en forma breve y clara, lo trata a profundidad; no es tampoco una historia de la Filosofía del Derecho, pero contiene los datos suficientes para entender como ha sido abordada la problemática del tema al través de la historia del pensamiento jurídico.

Aquí destaco, como referencia, cuatro temas abordados por Trueba en su obra. El tema tres, que se refiere a "La Persona", trata la temática tanto desde la esencia del ser humano,

\footnotetext{
1 Palabras pronunciadas en el Homenaje al Maestro Eugenio Trueba Olivares.

${ }^{2}$ Doctor en Filosofía, Universidad Nacional Autónoma de México, Facultad de Filosofía y Letras. Profesorinvestigador de la Universidad Autónoma de Aguascalientes.

${ }^{3}$ Ed. Universidad de Guanajuato, División de Ciencias Sociales y Humanidades, Departamento de Estudios de Cultura y Sociedad, 2009. (Tercera Edición).
} 
como "animal racional", o "animal reflexivo" que diría Teilhard de Chardin, porque no sólo sabe, sino que "sabe que sabe"; y trata también a la persona desde el plano existencial, como el "hacedor de sí mismo" que diría Mounier, "como un ser en camino" dice Trueba, por lo tanto con libertad y responsabilidad; y relaciona a la persona así considerada, con el Derecho que debe partir de éste modo de entender el ser humano.

En el tema 8 se refiere al debatido y clásico tópico de "Normas de moral y normas de Derecho", en donde Trueba no acepta la separación tajante que hace el racionalismo entre moral y Derecho; aunque establece importantes distinciones entre unas y otras normas.

El tema 11 se refiere a "La Justicia"; Trueba sigue en su exposición las enseñanzas del iusnaturalismo clásico versión aristotélico-tomista con influencia del personalismo, incluyendo en este apartado sugerentes reflexiones sobre la equidad como corrección concreta de la ley que se formula en abstracto.

Y el tema 14 es sobre "Derechos Humanos fundamentales"; lo considera un tema esencial del Derecho, entre otras cosas, porque la justicia se concretiza en esos derechos; señala las características de los derechos humanos, sus antecedentes y cómo los recogen las constituciones.

Este libro de Filosofía del Derecho de Eugenio Trueba tiene la ventaja de referirse a temas cotidianos de la juridicidad, que al ser tratados a profundidad acercan la reflexión filosófica a estudiantes y abogaos y rompe con la falsa creencia de que la Filosofía es solo para expertos.

Hemos reiterado que Eugenio Trueba, adherido a la tradición de iusnaturalismo clásico, considera que las normas jurídicas solo son obligatorias, solo constituyen autentico Derecho, si son justas, si sirven al desarrollo pleno de las personas. Destaco esto porque constituye la sustancia implícita de todo el libro y se hace explícito en muchos lugares. Trueba escribe:

Una ley arbitraria, lesiva de la persona y de la sociedad; contraria al bien individual o común, no obliga, aunque se haya expedido por quien puede hacerlo y de acuerdo con todas las formalidades del caso. ${ }^{4}$

Y en otro lugar, refiriéndose a las leyes injustas, el jurista guanajuatense escribe:

Se les niega entonces su naturaleza jurídica, sin importar que hayan tenido facticidad, es decir, que se hayan aplicado en la práctica y hayan tenido cierto grado de observancia, debido principalmente a la coacción que el Estado puede ejercer con tal objeto. Repitamos aquí que nada que dañe a la persona o a la sociedad misma pueda tener título de auténtica obligatoriedad. ${ }^{5}$

No quiero dejar de mencionar un precioso libro de Trueba Olivares denominado Ética Profesional para el ejercicio del Derecho. ${ }^{6}$ El tema siempre es actual; y más actual hoy por los días que corren. El libro es precioso, dije, porque no da recetas de moralina, sino reflexiones profundas de Filosofía del Derecho, acompañadas de datos históricos, anécdotas y pasajes

\footnotetext{
4 Ibidem, p. 30.

5 Ibidem, p. 36.

6 Ed. Universidad de Guanajuato, Guanajuato, 1993. 
literarios. Es una obra amenísima y erudita; muestra la enorme cultura del ilustre jurista guanajuatense.

Sin embargo, la gran obra de Filosofía del Derecho de Don Eugenio Trueba, es, según creo, El Hombre, la Moral y el Derecho. ${ }^{7}$ Constituye el desarrollo en grande, quiero decir en amplitud y profundidad, de su Guía Temática. Desde mi opinión, constituye uno de los mejores libros de la materia que se han escrito en México.

Destaco algunas cuestiones. El Capítulo Octavo, que titula “Los Valores Jurídicos”, prácticamente lo llena con reflexiones sobre la justicia desde distintos ángulos y en relación a otros valores y cuestiones afines. En ese lugar, en el punto 5 desarrolla el tema de "Justicia, Equidad y Caridad". Ya nos ha venido diciendo lo que es justicia, de acuerdo a la tradición tomista y personalista; ahora, aquí, la relaciona con la equidad y con la caridad.

La equidad o epiqueya es la justicia aplicada al caso concreto. Trueba, con gran claridad y sencillez, la va explicando. Sigue a Perelman, a Aristóteles y a Santo Tomás de Aquino. La equidad interviene, dice Trueba, "y nos ayuda a realizar la justicia material, como expresión de benignidad". Y en esta materia, como cada vez que lo considera oportuno, trae a cuento a Cervantes; aquí recuerda como Don Quijote aconseja a Sancho sobre el gobierno equitativo que debe ejercer en su ínsula: "Cuando debiere tener lugar la equidad, no cargues todo el rigor de la ley al delincuente, que no es mejor la fama del juez riguroso que la del compasivo". ${ }^{9}$

Luego el maestro Trueba se ocupa de la caridad como signo de amor y la relaciona con el mundo jurídico, directamente con la justicia.

Escribe esto:

No tratamos de identificar la caridad con la justicia, aunque tampoco la colocaríamos lejos de ella. La caridad, signo de amor, es tal vez una categoría diferente, pero no ajena. Y es indiscutible que históricamente la caridad ha precedido a la justicia del derecho positivo. Recordemos la profunda transformación sufrida por el mundo occidental cuando surge esta noción. La caridad era un concepto desconocido y los sentimientos de piedad no se consideraban dignos de los hombres fuertes y sabios, se ignoraba que la caridad reclama ser verdaderamente fuerte y sabio. El hombre débil es el menos preparado para practicar la caridad. ${ }^{10}$

Trueba considera que la caridad, como valor nuevo, a partir de la tradición cristiana, tiene gran influencia en el Derecho y se expresa en las "instituciones jurídicas positivas"; en aquellas normas que rescatan la dignidad de las mujeres, de los niños, los extranjeros, los esclavos, y los pobres en general.

\section{Comenta Trueba:}

La caridad va delante de las leyes y es muy posible que aquellas acciones tenidas como simples casos de magnanimidad no lo hayan sido, sino que más bien fueron acciones justas. Cuando menos debe admitirse que hay una zona en que justicia, equidad y caridad se confunden. Perelman va mas lejos y concluye su estudio sobre la justicia con las siguientes

\footnotetext{
7 Ed. Orlando Cardenas Velasco, 1986. Probablemente en Irapuato, en donde radicaba el editor.

8 Ibidem, p. 240.

9 Idem.

${ }^{10}$ Idem.
} 
palabras: "Todo sistema de justicia debería no perder de vista su propia imperfección y concluir que una justicia imperfecta, sin caridad, no es justicia. ${ }^{11}$

Esto hace recordar. Que nuestro filosofo del Derecho novohispano, Alonso de la Veracruz, decía en consonancia con lo anterior, refiriéndose a la administración de justicia:

"Puesto que los juicios son instituidos en favor de la caridad y de la justicia, no deben funcionar en contra la caridad y la justicia". ${ }^{12}$

Pienso en estos conceptos del maestro Don Eugenio Trueba y los contrasto con la realidad mexicana que vivimos; lo que hago es, como decía frecuentemente Bartolomé de Las Casas, "juntar el derecho con el hecho".

Evoco a los miles de desaparecidos y lamento la enorme corrupción impune...

Y en concreto, considero la desaparición y el muy posible cruelísimo asesinato de los cuarenta y tres estudiantes de la Normal Rural Isidro Burgos, de Ayotzinapa, Guerrero, a fines de septiembre de 2014, es sólo, como se dice, la punta de iceberg, de la sistemática y reiterada práctica de violación de derechos humanos en México, siendo las víctimas los más pobres. El caso de Ayotzinapa es emblemático, porque muestra el desprecio por la vida de los pobres. Así, de manera directa y muy cruel, se atenta contra su vida; lo mismo se hace, sin rubor y al amparo de la Ley, en contra de sus condiciones materiales de vida, despojándose de ellas a los pobres, a sus pueblos y comunidades. Se les priva de su tierra, de su agua y de su mismísimo alimento, el maíz, que es carne, sangre y cultura del pueblo. Y ese despojo, esa rapiña, por las condiciones materiales de vida de los pobres, se hace no violando las normas jurídicas, sino con el aval de la Ley. Esto es posible, al hacerse todas las reformas legislativas neoliberales con las que se ha desmontado el Estado Social de Derecho. Con la reforma agraria neoliberal, con la reforma laboral, con la reforma energética, se consolida, en contra de los derechos humanos de los pobres, la legalidad de la injusticia. ${ }^{13}$ Con la Ley es más fácil el despojo; y con la Ley en contra, mucho más difícil defender derechos. Esos derechos que son colectivos, que son sociales y que hacen posible la vida y la dignidad de las personas.

Lleva razón Eugenio Trueba, el problema de la injusticia o no vigencia de la justicia, no es por desconocimiento de la misma, pues, agrega, "hay vías orientadoras, experiencias propias e históricas, opiniones prudentes, sentimiento universales e instituciones suficientes para procurarla, o al menos para aproximarse a ella". ${ }^{14}$

El problema de la justicia, apunta el maestro, "no representa una crisis de orden especulativo, sino que es un problema practico, de ejercicio, de buena voluntad". ${ }^{15}$

Me atrevo a decir, que parte de ese problema practico está en el modo en que se reproduce el Derecho por medio de su enseñanza. Si esto es así, es urgente retomar en la educación

\footnotetext{
${ }^{11}$ Ibidem, p. 241.

${ }^{12}$ Alonso de la Veracruz, Sobre los diezmos, texto íntegro en castellano del tratado De decimis, Trad. Rubén Pérez Azuela, O. S. A., Ed. Organización de Agustinos de Latinoamérica (OALA). México, 1994, Parágrafo 382, p. 130.

${ }^{13}$ DUSSEL, Enrique, Para una ética de la liberación latinoamericana, Tomo II, Ed. Siglo XXI, Buenos Aires, 1973 , p. 66.

14 TRUEBA OLIVARES,Eugenio, El Hombre... Op. Cit. p. 242.

${ }^{15}$ Idem. 
jurídica los aspectos más profundos del Derecho, precisamente en los que maestros como Trueba se han empeñado en la enseñanza jurídica.

Al maestro Trueba no le gustan las utopías, desconfía de ellas como de los sueños; ${ }^{16}$ a las utopías ha dedicado un magnífico libro. ${ }^{17}$ Confieso que a mi me gustan y encuentro valioso el pensamiento utópico. No voy a entrar aquí en una polémica. Digo esto, porque en los tiempos que corren, puede ganar la impaciencia que a veces impulsa a ese pensamiento utópico.

La propuesta teórica y de vida de Trueba está más bien en una paciente, pero constante voluntad de contribuir a que cada quien tenga lo suyo en la realidad, esto es, viva su dignidad y cuente con las condiciones materiales para una vida plena.

Esta voluntad constante que forma parte de la justicia, es la propuesta que el maestro Trueba nos hace a todos, especialmente a los juristas; precisamente para que la justicia sea realidad.

Guanajuato, Gto. a 16 de Febrero de 2015

${ }^{16}$ Cfr. Eugenio TRUEBA OLIVARES, Ensayo sobre utopías, Centro de Investigaciones Humanistas de la Universidad de Guanajuato, 1983, p. 10.

${ }^{17}$ Idem. 